\title{
The zona orbicularis of the hip joint: anatomical study and review of the literature
}

\author{
Alexandra Fayne ${ }^{1}$, Peter Collin ${ }^{2}$, Melissa Duran ${ }^{1}$, Helena Kennedy ${ }^{2}$, Kiran Matthews ${ }^{3}$, \\ R. Shane Tubbs ${ }^{4,5}$, Anthony V. D'Antoni ${ }^{6}$ \\ ${ }^{1}$ SUNY Downstate College of Medicine, New York, USA \\ ${ }^{2}$ New York University School of Medicine, New York, USA \\ ${ }^{3}$ City University New York, New York, USA \\ ${ }^{4}$ Seattle Science Foundation, Seattle, WA, USA \\ ${ }^{5}$ Department of Anatomical Sciences, St. George's University, Grenada, West Indies \\ ${ }^{6}$ Division of Anatomy, Department of Radiology, Weill Cornell Medical College, New York, USA
}

\begin{abstract}
Objectives: Although it is used as a landmark during various orthopedic procedures of the hip, few studies have focused on the anatomy of the zona orbicularis. Therefore, the purpose of the present research was to study its morphology to improve our understanding of its structure and potential variation.

Methods: Ten adult cadavers (four males and six females) underwent dissection of the left and right hip joints to observe the morphology and location of the zona orbicularis. A digital caliper was used to measure the length and width of the zona orbicularis.

Results: We found a zona orbicularis on all sides and that when present anteriorly, many of the inferior fibers of the zona orbicularis were confluent with the fibers of the iliofemoral ligament. The mean length for right sides was $35.95 \mathrm{~mm}$ and the mean length for left sides was $43.93 \mathrm{~mm}$. The mean width for right sides was $3.74 \mathrm{~mm}$ and the mean width for left sides was $4.4 \mathrm{~mm}$. There were no significant differences between the right and left sides for zona orbicularis length or width. There was no significant association between age and sex but a statistically significant correlation ( $r=0.959)$ between right and left zona orbicularis lengths $(p=0.041)$. However, there was no significant correlation between the right and left zona orbicularis widths $(p>0.05)$. The fibers of the zona orbicularis were found to be thicker and more visible along the posterior aspect of the femoral neck.

Conclusion: Anatomically, the zona orbicularis is a consistent structure of the hip joint capsule. This structure can be seen on high resolution imaging such as MRI and magnetic resonance arthrography. The lengths of this structure may differ between sides, although based on our study, there were no differences between left and right side widths or between sexes or among ages.
\end{abstract}

Keywords: anatomy; capsule; hip joint; ligaments, surgery

Anatomy 2017;11(3):133-136 @2017 Turkish Society of Anatomy and Clinical Anatomy (TSACA)

\section{Introduction}

The zona orbicularis is one of the ligaments that constitute the capsular hip joint. ${ }^{[1]}$ It lies underneath the synovial capsule with the fibers located in a horseshoe or circumferential pattern around the femoral neck. ${ }^{[2,3]}$ The fibers are most abundant posteriorly and inferiorly and move in a posterolateral to anteromedial fashion, placing them exactly perpendicular to the femoral neck (Figure 1). Anteriorly, they blend with the iliofemoral ligament, while superiorly the zona orbicularis blends with the ischiofemoral ligament and connects to the base of the greater trochanter..$^{[3-5]}$ As it moves inferiorly, the zona orbicularis is twisted from posterolateral to anteromedial. The zona orbicularis, once called the anular ligament of the hip, orbicular zone, ring ligament and zonular band, has been hypothesized to contribute to hip joint stability and resistance to distraction of the hip. ${ }^{[5-7]}$

Surgically, the zona orbicularis is used as a landmark. In arthroscopic procedures, it is used as a landmark in lateral approaches to the hip for repair of peripheral compartment 
pathologies. ${ }^{[3,8-10]}$ In anterolateral approaches, the zona orbicularis is used as a landmark to avoid injury to the branches of the lateral circumflex femoral arteries. Such injuries can disrupt blood flow to the neck and head of the femur. ${ }^{[10]}$ In order to relieve the pain from a symptomatic internal snapping hip, an arthroscopic approach can be pursued after all medical and conservative measures have failed. This procedure uses an anterior portal approach to release the iliopsoas tendon. In order to visualize the tendon, the fibers of the zona orbicularis are used as a landmark..$^{[1,12]}$

Few studies have focused on the anatomy of the zona orbicularis. ${ }^{[4,13]}$ Therefore, the purpose of the present research was to study the morphology of the zona orbicularis and its anatomical variation to improve our understanding of its structure.

\section{Materials and Methods}

Ten embalmed adult cadavers (four males and six females) underwent dissection of the left and right hip joints using blunt and sharp dissection. Specifically, the dissections focused on observing the morphology and location of the zona orbicularis. The mean (SD) age at death of the specimens was 82.1 (14.5) years with a range from 54 to 98 years.

For anterior dissections, the cadavers were placed supine. The origins of the sartorius, rectus femoris, and pectineus muscles were reflected inferiorly to expose the hip joint. The femoral vessels and nerves were then cut to reach the iliopsoas muscle and tendon, which was removed from the lesser trochanter of the femur to expose the joint capsule. At this point, the iliofemoral ligament and pubofemoral ligament were visible anteriorly.

In the prone position, the gluteus maximus was dissected; the medius and minimus were reflected inferiorly from their insertions on the greater trochanter of the femur. The piriformis, obturator internus, gemelli, quadratus femoris, and obturator externus muscles were cut from their superior attachments to reveal the posterior aspect of the fibrous capsule of the hip joint.

Next, an incision was made spanning medial to lateral along the more proximal and superior aspect of the anterior head of the femur. Care was taken to avoid the neck of the femur. The cut was made deeply in order to separate the femoral head completely from the capsule. Blunt dissection was then used to remove the rest of the capsule inferiorly to expose the zona orbicularis completely. Photographs were taken of the anatomical dissections. A digital caliber was used to measure the length and width of the zona orbicularis. Data were entered into SPSS version 22 for statistical calculations with statistical significance set at $\mathrm{p}<0.05$.

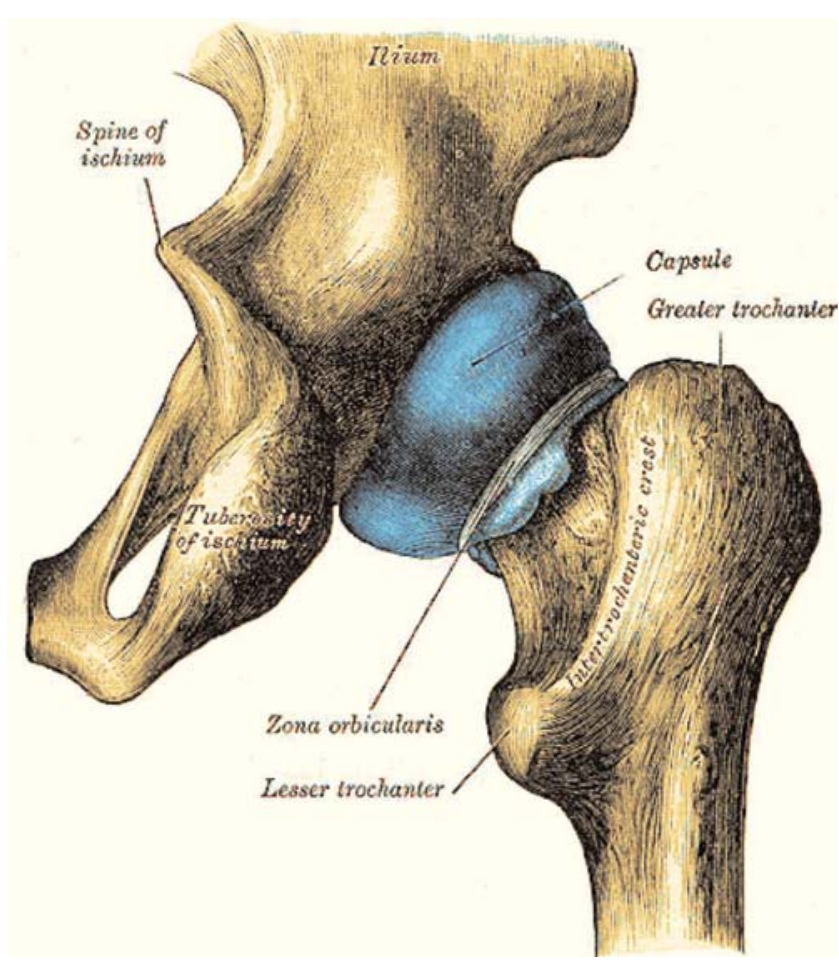

Figure 1. Schematic drawing of the zona orbicularis and surrounding relationships via posterior dissection from Gray's Anatomy, 1918 (public domain). [Color figure can be viewed in the online issue, which is available at www. anatomy.org.tr]

\section{Results}

When present anteriorly, many of the inferior fibers of the zona orbicularis were confluent with the fibers of the zona orbicularis. Table 1 shows the measurements of the mean lengths and widths of the zona orbicularis. There were no significant differences between the means of the right and left sides for zona orbicularis length or width. The ranges for width for left and right sides was $3.17-6.32 \mathrm{~mm}$ and $2.03-4.61 \mathrm{~mm}$, respectively. The ranges for length for left and right sides was 31.43-70.54 $\mathrm{mm}$ and $32.64-44.61 \mathrm{~mm}$, respectively. There was no significant association between age and sex using a Mann-Whitney $U$ test $(\mathrm{p}>0.05)$. A paired sample corre-

Table 1

Measurements of the zona orbicularis.

\begin{tabular}{|c|c|c|c|}
\hline & \multicolumn{2}{|c|}{ Mean (SE) } & \multirow[b]{2}{*}{ p-value } \\
\hline & Right sides (mm) & Left sides (mm) & \\
\hline Length & $35.95(2.9)$ & $43.93(4.4)$ & 0.249 \\
\hline Width & $3.74(0.4)$ & $4.4(0.34)$ & 0.229 \\
\hline
\end{tabular}

SE: standard error 
lation demonstrated a statistically significant correlation $(r=0.959)$ between right and left zona orbicularis lengths ( $\mathrm{p}=0.041$ ) (Figures 2 and 3) but no significant correlation between right and left zona orbicularis widths $(p>0.05)$. The zona orbicularis fibers were found to be thicker and more visible along the posterior aspect of the femoral neck.

\section{Discussion}

We found a zona orbicularis on all sides and when present anteriorly, many of the inferior fibers of the zona

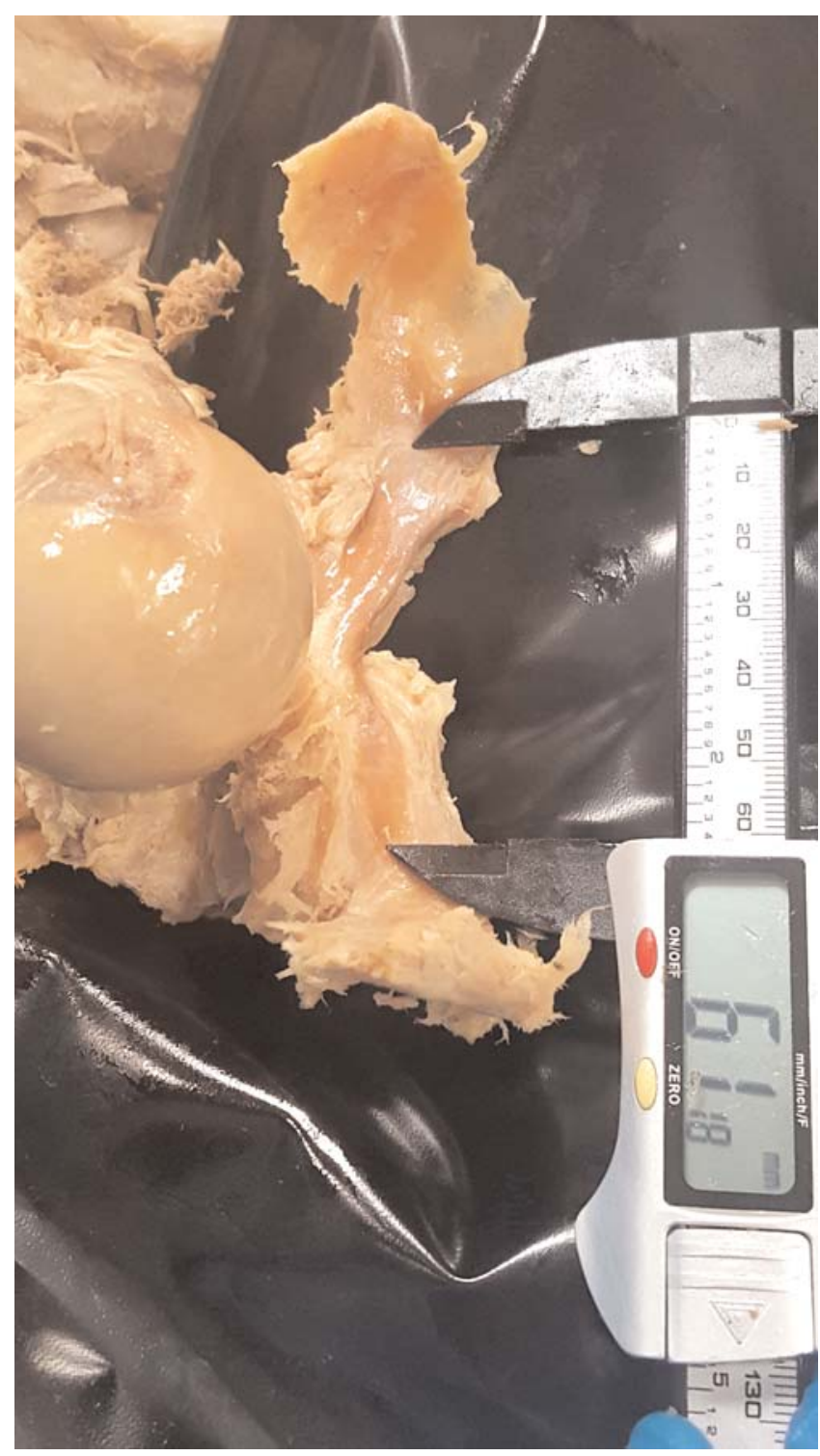

Figure 2. Cadaveric example of the right zona orbicularis and its length. [Color figure can be viewed in the online issue, which is available at www. anatomy.org.tr] orbicularis were confluent with the fibers of the iliofemoral ligament. The mean length for right sides was $35.95 \mathrm{~mm}$ and the mean length for left sides was $43.93 \mathrm{~mm}$. The mean width for right sides was $3.74 \mathrm{~mm}$ and the mean width for left sides was $4.4 \mathrm{~mm}$. There were no significant differences between right and left sides for zona orbicularis length or width. There was no significant association between age and sex but a statistically significant correlation $(\mathrm{r}=0.959)$ between right and left zona orbicularis lengths $(\mathrm{p}=0.041)$. However, there was no significant correlation between right and left zona orbicularis widths $(\mathrm{p}>0.05)$. The fibers of the zona

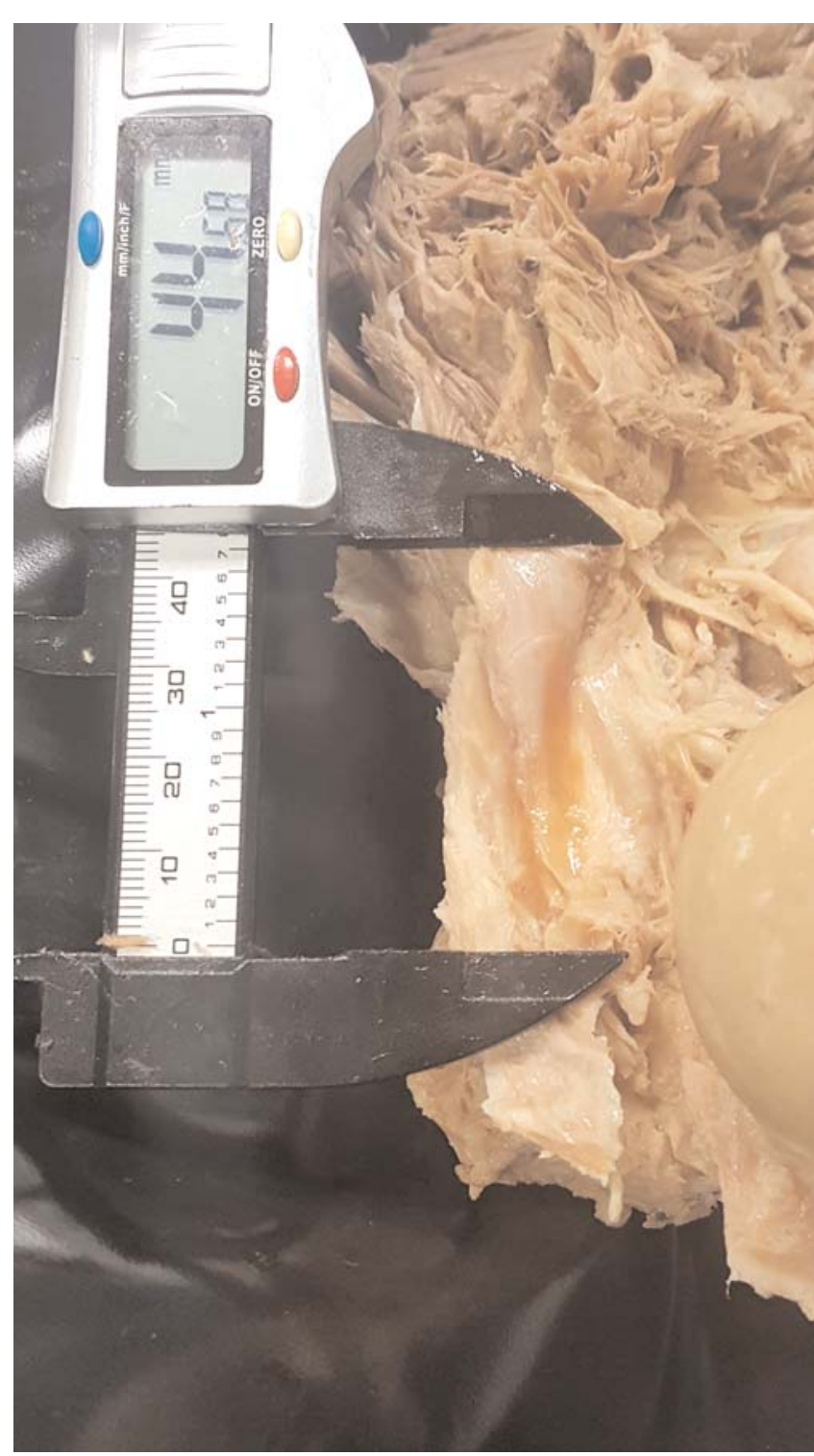

Figure 3. Cadaveric example of the left zona orbicularis and its length. [Color figure can be viewed in the online issue, which is available at www. anatomy.org.tr] 
orbicularis were found to be thicker and more visible along the posterior aspect of the femoral neck.

Using magnetic resonance arthrography, Malagelada et al.$^{[5]}$ found that the zona orbicularis was absent anteriorly on the majority of sides. Using MRI, it was absent posteriorly on roughly half of sides, absent inferiorly on roughly one third of sides and anteriorly on $8 \%$ of sides. Their study also pointed out that the zona orbicularis was often congruent with the periphery of the head of the femur and its narrowest point was at the isthmus of the neck of the femur. Malagelada et al ${ }^{[5]}$ concluded that the zona orbicularis is most consistently identified when the joint is distended and that it is aligned perpendicular to the long axis of the neck of the femur. These authors also supported the hypothesis that the zona orbicularis functions as a gasket that resists the distraction of the head of the femur and thus contributes to synovial fluid circulation.

Ito et al ${ }^{[6]}$ hypothesized and then concluded that the zona orbicularis functions in resisting hip distraction. In seven cadaveric hips, in a direction parallel to the body of the femur, the hip joint was distracted. Next, the overlying soft tissues were sequentially dissected: (1) intact specimen (muscle and skin removed), (2) capsule opened, (3) iliofemoral ligament cut, (4) circumferentially capsule incised, (5) partially resected capsule, (6) completely resected capsule, (7) radially incised acetabular labrum, and (8) completely resected acetabular labrum. The reduction of the distraction load was greatest between the partially resected capsule phase and completely resected capsule phase at 1,3 , and $5 \mathrm{~mm}$ joint distraction.

\section{Conclusion}

Anatomically, the zona orbicularis is a consistent structure of the hip joint capsule. This structure can be seen on high resolution imaging such as MRI and magnetic resonance arthrography. The lengths of this structure may differ between sides although based on our study, there were no differences between left and right sided widths or between sexes or among ages.

\section{Acknowledgements}

The authors thank those who donated their bodies for medical study. Also, the authors thank the following individuals for their assistance in the dissections: Orin Imani Donaldson, Samantha Syldort, and Melissa Evelyn.

\section{References}

1. Standring S. Gray's anatomy: the anatomical basis of clinical practice. 41st ed. New York (NY): Elsevier; 2015.

2. Odgers P. Two details about the neck of the femur. (1) The eminentia. (2) The empreinte. J Anat 1931;65:352.

3. Field RE, Blakey C, Malagelada F. Anatomy: capsule and synovium. In: McCarthy JC, Noble PC, Villar RN, editors. Hip joint restoration: worldwide Advances in arthroscopy, arthroplasty, osteotomy and joint preservation surgery. Berlin: Springer; 2017.

4. Wagner FV, Negrão JR, Campos J, Ward SR, Haghighi P, Trudell DJ, Resnick D. Capsular ligaments of the hip: anatomic, histologic, and positional study in cadaveric specimens with MR arthrography. Radiology 2012;263:189-98.

5. Malagelada F, Tayar R, Barke S, Stafford G, Field RE. Anatomy of the zona orbicularis of the hip: a magnetic resonance study. Surg Radiol Anat 2015;37:11-8.

6. Ito H, Song Y, Lindsey DP, Safran MR, Giori NJ. The proximal hip joint capsule and the zona orbicularis contribute to hip joint stability in distraction. J Orthop Res 2009;27:989-95.

7. Field RE, Rajakulendran K. The labro-acetabular complex. JBJS 2011;93(S2):22-7.

8. Sampson TG. Lateral approach to hip arthroscopy. In: Sekiya J Safran M, Ranawat A, Leunig M, editors. Techniques in hip arthroscopy and joint preservation surgery: with expert consult access. Philadelphia (PA): Saunders/Elsevier; 2011. pp. 95-104.

9. Aprato A, Giachino M, Masse A. Arthroscopic approach and anatomy of the hip. Muscles Ligaments Tendons J 2016;6:309.

10. Bedi A, Galano G, Walsh C, Kelly BT. Capsular management during hip arthroscopy: from femoroacetabular impingement to instability. Arthroscopy 2011;27:1720-31.

11. Hwang DS, Hwang JM, Kim PS, Rhee SM, Park SH, Kang SY, Ha YC. Arthroscopic treatment of symptomatic internal snapping hip with combined pathologies. Clin Orthop Surg 2015;7:158-63.

12. Yen YM, Lewis CL, Kim YJ. Understanding and treating the snapping hip. Sports Med Arthrosc Rev 2015;23:194-9.

13. Magerkurth O, Jacobson JA, Morag Y, Caoili E, Fessell D, Sekiya JK Capsular laxity of the hip: findings at magnetic resonance arthrography. Arthroscopy 2013;29:1615-22.

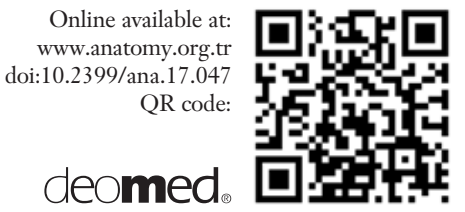

\author{
Correspondence to: R. Shane Tubbs, PhD, PA-C, MS, BS \\ Seattle Science Foundation, 550 17th Avenue, \\ Suite 600 , Seattle, WA 98122, USA \\ Phone: +1 2067326500 \\ e-mail: shanet@seattlesciencefoundation.org \\ Conflict of interest statement: No conflicts declared.
}

This is an open access article distributed under the terms of the Creative Commons Attribution-NonCommercial-NoDerivs 3.0 Unported (CC BY-NCND3.0) Licence (http://creativecommons.org/licenses/by-nc-nd/3.0/) which permits unrestricted noncommercial use, distribution, and reproduction in any medium, provided the original work is properly cited. Please cite this article as: Fayne A, Collin P, Duran M, Kennedy H, Matthews K, Tubbs RS, D’Antoni AV. The zona orbicularis of the hip joint: anatomical study and review of the literature. Anatomy 2017;11(3):133-136. 